\title{
Entrevista al Dr. JaVier Arias Stella y un ANIVERSARIO MÁS DE SU DesCUBRIMIENTO.
}

\author{
Interview with Dr. Javier Arias Stella and another anniversary of his discovery.
}

\section{Ernesto Nava Carrión*}

\section{RESUMEN}

En este año se conmemoró el sexagésimo aniversario de la primera publicación del Dr. Javier Arias Stella que describió los cambios inducidos en el endometrio por acción de las hormonas de la gestación, descubrimiento conocido como "Fenómeno Arias Stella". Por este motivo, se presenta una entrevista, inédita, que se realizó a mediados del 2004, para comprender su personalidad y la magnitud de su aporte a la ciencia médica.

Palabras claves: Entrevista, patología, medicina, Fenómeno Arias Stella.

\section{Abstract}

This year we celebrated the sixtieth anniversary of the first publication of Dr. Javier Arias Stella, who described the changes in the endometrium induced by action of the hormones of pregnancy, discovery known as « Arias Stella phenomenon «. For this reason, we present an unpublished interview, which took place in mid-2004, to understand his personality and the magnitude of his contribution to medical science.

Keywords: Interview, pathology, medicine, Arias Stella phenomenon.

\section{INTRODUCCIÓN}

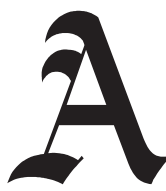

mediados de agosto del presente año se conmemoró el sexagésimo aniversario de la primera publicación delDr.Javier AriasStella que describía

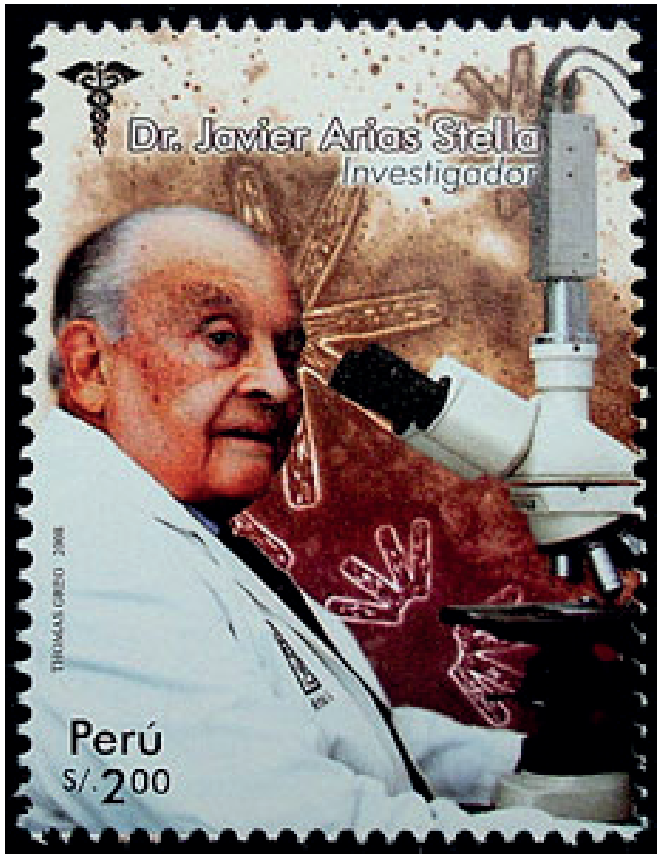

Sello postal con efigie del Dr. Javier Arias Stella.

los cambios inducidos en el endometrio por acción de las hormonas de la gestación.

Por este motivo, he decidido dar a conocer una entrevista, inédita, que se realizó a mediados del 2004 con motivo del quincuagésimo aniversario de la publicación.

* Médico patólogo. Ex patólogo del Hospital Nacional Arzobispo Loayza de Lima. Profesor (r) de la Universidad Peruana Cayetano Heredia. Actual director de Instituto de Patología de la Universidad Nacional Mayor de San Marcos en el HNAL. 


\section{JAVIER ARIAS STELLA, CINCUENTA AÑOS DESPUÉS (2004)}

En agosto de 1954 se publicó en una de las más serias y afamadas revistas médicas norteamericanas, el A.M.A. Archives of Pathology, vol. 58, pp. 112-128, un artículo titulado "Atypical endometrial changes associated with presence of chorionic tissue", cuyo autor era el entonces joven médico peruano Dr. Javier Arias Stella, quien estaba cursando su posgrado de patología en los Estados Unidos de Norteamérica bajo la tutela de uno de los más renombrados científicos del ramo, el Dr. Fred Stewart.

Quizás en aquel momento, sobre todo para los ajenos a la profesión médica, probablemente, no les llegó la noticia o no le prestaron la debida atención. Hoy, ese descubrimiento y aporte científico es conocido con el nombre propio de "Fenómeno Arias Stella", privilegio que muy pocos investigadores pueden ostentar y que tiene un profundo significado de orgullo personal, profesional y, por qué no decirlo, nacional, por su connotación y reconocimiento mundial.

Como discípulo del Dr. Javier Arias Stella, creí pertinente recordar este suceso y quién mejor que él mismo absolviera algunas preguntas, para entender y comprender su personalidad y la magnitud de su aporte a la ciencia médica mundial.

Por este motivo, nos apersonamos al actual Instituto de Patología que él ha fundado y que lleva su nombre, donde diariamente ejecuta una incansable labor asistencial, de investigación y docencia.

Nos recibió en su despacho rodeado de libros, fotos, caricaturas y otros recuerdos relacionados a su fructífera existencia; $y$, con la confianza que siempre me ha brindado, le expliqué el motivo de mi visita y la posibilidad de la entrevista con motivo del aniversario 50 de la publicación de su hallazgo, además de conocer algunos aspectos de su vida que pudieran estar conexos al tema a tratar, a lo que accedió muy gustoso.

\section{Don Javier. ¿Cómo describiría su descubrimiento a la comunidad?}

Como una alteración histológica, microscópica, que ocurre en el endometrio, que es la capa interna o mucosa del útero en la que células endometriales, de las glándulas, simulan la morfología de células atípicas o cancerosas. La contribución consistió en demostrar que estos cambios no eran neoplásicos, como frecuentemente eran confundidos, y que estaban en relación con las hormonas que produce la placenta.

\section{¿Dónde inició este estudio, en dónde lo desarrolló y en qué lugar lo culminó?}

Las primeras observaciones las hice cuando todavía era estudiante de medicina, en dos pacientes del pabellón 5 del Hospital Arzobispo Loayza. Culminé el estudio en el Memorial Center for Cancer de Nueva York. 
¿Cuál o cuáles fueron las proyecciones que ha tenido dicho aporte a la ciencia médica y al paciente?

El reconocimiento de esta alteración, hoy incorporada en el acervo rutinario de los diagnósticos anatomopatológicos, ha evitado que muchas mujeres sean sometidas innecesariamente a la extirpación del útero y ha contribuido al diagnóstico en las biopsias endometriales de múltiples condiciones ligadas a la gestación y a la presencia o proliferación del tejido placentario que ocurre a diario en la patología ginecológica.

¿Quién o quiénes considera Ud. los personajes que han influido en esta etapa decisiva de su profesión?

Mis dos grandes maestros. El profesor Pedro Weiss Harvey, en el Perú, y el profesor Fred W. Stewart en EE.UU.

¿Qué significación tiene para $\mathrm{Ud}$. ser reconocido en nuestro país y en el mundo como una figura representativa de la Medicina Peruana?

Es muy gratificante saber que la propia existencia se justifica al haber contribuido, en alguna forma, al progreso del conocimiento médico.
¿Dr. Arias: me podría Ud. Mencionar las distinciones nacionales e internacionales que usted ha recibido en relación a su descubrimiento y a su brillante carrera de investigador?

Las distinciones más importantes:

- Premio Fomento de la Cultura "Hipólito Unanue" otorgado en el ramo de Ciencias, 1959, Perú.

- Premio Roussel, otorgada a la mejor publicación anual médica científica peruana, siendo la primera vez que se otorgó el premio, como reconocimiento al aporte sobre los cambios endometriales, 1960, Perú.

- Premio Fred W. Stewart, por reconocimiento a un aporte transcendente en el avance de la oncología en el mundo, otorgado por el Memorial Sloan Kettering Cancer Center, 1991, New York, EE.UU. de N.A.

- Premio Southern, Medalla Cristóbal de Losada y Puga a la Creatividad Humana, 1998, Lima, Perú.

\section{¿Por qué decidió estudiar la carrera médica y en especial la patología?}

Desde que tuve uso de razón siempre dije que habría de ser médico. Es probable que mi padre me hablara con elogio sobre mi abuelo Enrique Arias Soto, que fue presidente de la Academia Nacional de Medicina, y que esto hubiera influenciado en esa temprana decisión. 
¿Cómo docente universitario, cuál o cuáles serían las sugerencias que daría a la enseñanza universitaria?

Es indispensable frenar la multiplicación de facultades de medicina, garantizar la existencia de un profesorado a tiempo completo y dedicación exclusiva, y restituir la obligatoriedad de las tesis de grado para el bachillerato.

¿Sugerencias y consejos a los estudiantes y profesionales, en la actualidad?

Difícil respuesta en un mundo tan velozmente cambiante como el presente. Solidaridad y comportamiento ético creo que son cada vez necesarios.

¿Cómo maestro cree haber cumplido a cabalidad esta labor?

Siempre me persigue la idea de nunca hacer lo suficiente.

\section{¿A qué maestro o maestros universitarios admira más y por qué?}

Además de los dos ya mencionados, guardo particular respeto por los doctores Alberto Hurtado y Julio C. Tello, por ser ejemplos de peruanos de acción más que de palabras.
¿Cómo ha superado los obstáculos en su vida?

Con optimismo. En la universidad, antes que se forme la UPCH, por mi iniciativa, se construyó un nuevo Instituto de Patología, equipado en la frontera del conocimiento técnico del momento por la Fundación Kellogg, que había becado mis estudios de postgrado. Hoy la iniciativa de mi hijo Javier Luis ha hecho posible crear el primer Instituto de Patología privado en el Perú.

En el campo político he conocido la adversidad de la prisión y el destierro por defender mis principios cívicos que han permanecido $y$ permanecen inalterables.

Si no tiene inconveniente, quisiera que me respondiera unas preguntas de índole personal. ¿Qué planes tiene Ud. para el futuro?

Mi techo es bajo. De inmediato estoy concluyendo el estudio presentado en el II Congreso Intercontinental de Patología, realizado en Iguazú en junio de este año, sobre una nueva alteración en el cérvix uterino. También debe publicarse pronto el cuento para estudiantes de medicina "Historia de un epónimo médico". Trabajo simultáneamente en varios temas en colaboración con los otros miembros de nuestro instituto. 


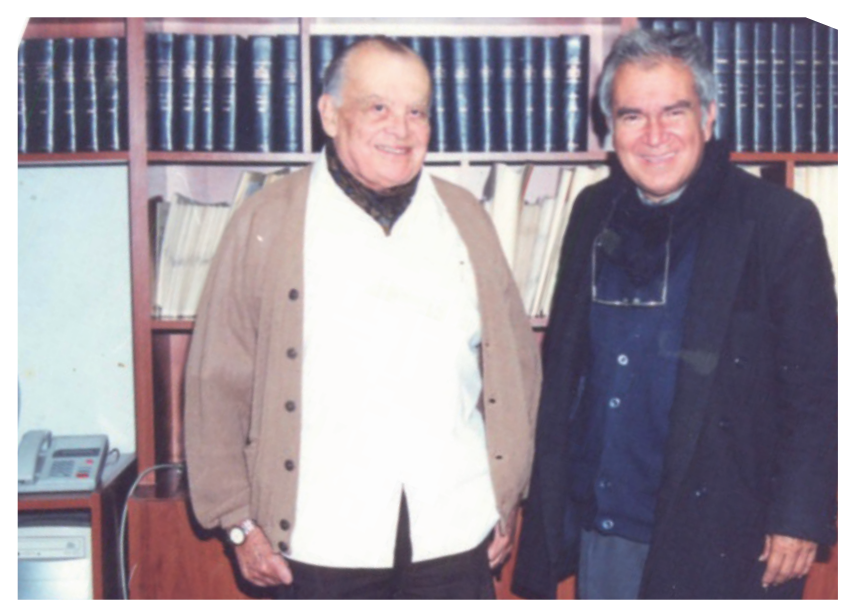

Dr. Javier Arias Stella con su discípulo Dr. Ernesto Nava Carrión, en el día de la entrevista. (agosto, 2004).

¿Piensa Ud. como esposo y padre de familia, que su entorno familiar ha influido en su fructífera existencia?

Nancy, mi esposa. Patricia, Javier Luis, José Luis y Fernando Luis, mis hijos son mis mejores estímulos y copartícipes de mis logros.

\section{¿A qué personajes de la historia admira Ud. y por qué?}

En el campo político y social, a Gandhi, que predicando la paz y la no violencia logró la independencia de su pueblo. En el campo médico, a Rudolf Virchow, el más grande patólogo de todos los tiempos.

Luego de la entrevista, don Javier me invitó y acompañó a visitar las modernísimas instalaciones del Instituto de Patología que ha fundado y dirige, mostrándome el alto nivel científico y técnico que allí se ha alcanzado.
En el transcurso de la entrevista, pude apreciar a don Javier Arias Stella desarrollar su cotidiana existencia, con gran tesón, responsabilidad e indomable voluntad de trabajo, como médico, investigador y docente.

De esta manera, he dado a conocer la faceta científica y humana de este eminente peruano que, por la magnitud de sus conocimientos, producción intelectual y por las diferentes áreas en las que ha incursionado siempre con éxito, puede ser considerado un humanista, que ha constituido meritoriamente una sólida escuela médica de anatomía patológica, que proyecta y seguirá proyectando, en el Perú y en el mundo, los conocimientos que nos ha vertido.

Por lo expuesto propusimos a Serpost del Perú, la emisión de un sello postal que llevase su efigie, como un homenaje de la nación peruana por sus aportes científico, además de universalizar su figura no solamente en el ambiente medico sino en todas las disciplinas. Para desarrollar estas gestiones contamos con el valioso apoyo del Lic. Luis Alva, jefe de la Oficina de Filatelia de Serpost. Este sello postal se puso a circulación el 22 de agosto del 2008. Para finalizar, nuestro deseo es siempre contar con su presencia, para que nos siga nutriendo con sus aportes y atinados consejos.

\section{CORRESPONDENCIA}

Dr. Ernesto Nava Carrión. Correo electrónico: doctorernestonava@hotmail.com 